\title{
Effects of Rare Earth Neodymium on Microstructure and Mechanical Properties of Mg-Ce-Zn-Zr Alloy
}

\author{
Mohd Zaidi Hamzah $^{1}$, R. Ahmad ${ }^{1}$, M. B. A. Asmael ${ }^{1}$, Z. M. Sheggaf ${ }^{2}$ \\ ${ }^{1}$ Department of Mechanical Engineering, Politeknik Sultan Haji Ahmad Shah, Kuantan Pahang, Malaysia. \\ ${ }^{2}$ Department of Manufacturing and Industrial Engineering, Universiti Tun Hussein Onn Malaysia, Batu \\ Pahat Johor, Malaysia. \\ * Corresponding author. email: mzaidi272@gmail.com, roslee@uthm.edu.my \\ Manuscript submitted April 15, 2017; accepted September 8, 2017. \\ doi: 10.17706/ijmse.2017.5.4.133-139
}

\begin{abstract}
The effects of (1.0, 2.0 and 3.0 wt.\%) rare earth Neodymium, Nd addition on microstructure and mechanical properties of as-cast Mg-Ce-Zn-Zr alloy (base alloy) were investigated. The solidification as cast microstructures and phase constitution were characterized by using optical microscopy (OM), scanning electron microscopy (SEM), energy-dispersive spectrum (EDS) and X-ray diffraction (XRD). Tensile properties of the investigated alloys were measured by tensile test including yield strength, ultimate tensile strength and elongation. Results indicated that the solidification microstructures of Nd-containing alloys are mainly consists of two phases, $\alpha-\mathrm{Mg}$ and $(\mathrm{Mg}, \mathrm{Zn})_{12}(\mathrm{Ce}, \mathrm{Nd})$ phase. $\mathrm{Nd}$ addition led to significant grain refinement and increased volume fraction of $(\mathrm{Mg}, \mathrm{Zn})_{12}(\mathrm{Ce}, \mathrm{Nd})$ phases. Furthermore, $\mathrm{Nd}$ addition significantly decreased the average grain size of as-cast base alloys by approximately 19.68\%. Both yield strength and ultimate tensile strength of $\mathrm{Nd}$-containing alloys also increased, whereas significantly detrimental to elongation which decreased by $19.7 \%$.
\end{abstract}

Key words: magnesium alloy, rare earth, neodymium, microstructure, tensile propertie.

\section{Introduction}

The most outstanding characteristic of magnesium is its density $1.74 \mathrm{~g} / \mathrm{cm}^{3}$, which is the lowest of all the structural metals, therefore, its alloy are used where light weight is an important consideration. Vehicle light weighting for example is among the available strategies to improve the fuel economy and performance of vehicle and thus has attracted major automotive companies to increase the usage of magnesium alloys in their structure and power train components particularly engine block. In recent years, there have been renewed interest from aerospace, military industries and medical application in development of new magnesium alloys [1]. Moreover magnesium alloys have better castability over other cast metals such as aluminium and copper, and molten magnesium does not attack iron, thus magnesium alloys can be melted and held in crucibles and molds fabricated from ferrous materials [2].

Rare earth (RE) elements such as Cerium (Ce), Gadolinium (Gd) and Neodymium (Nd) are among the commercially used RE in magnesium alloys that have been found to simultaneously generate favorable effects on microstructure and increase mechanical properties of magnesium alloys [3]. It is well known that RE element additions contributed to reinforcing grain boundaries by the formation of RE-containing intermetallic phases crystallized along grain boundaries and strengthens the $\alpha$-matrix by RE supersaturated in solid solution, thereby resulting in increasing alloy strength [4]. In addition, formation of 
intermetallic phase on grain boundaries of the cast alloys, considered as the main cause that led to significant grain refinement, particularly in low solubility $\mathrm{RE}$ in $\mathrm{Mg}$ ( $\mathrm{La}, \mathrm{Ce}, \mathrm{Nd}$ ) due to restriction of grains growth of segregated RE elements at front of growing liquid/solid interface [3].

Based on critical review on the literature work of Mg-RE alloy systems, Tekumulla et al. [5] summarized that Mg-Zn-RE (containing single RE or more combination RE elements) exhibited the best combination of both strength and ductility. Traditionally, additions of RE have been made in misch metals form which are unspecified blends of elements of $\mathrm{Ce}, \mathrm{La}, \mathrm{Nd}, \mathrm{Pr}$ and $\mathrm{Sm}$. Recent study found that individual element $\mathrm{La}, \mathrm{Ce}$ and $\mathrm{Nd}$ has influence on creep properties differently in die-cast AE44 alloy. Spurred by the growing realization that each of the $\mathrm{RE}$ alloying elements has its own effects, it is therefore a need to investigate the effects of individual $\mathrm{RE}$ element in $\mathrm{Mg}$ alloys in order to attribute properly its contribution on microstructure and mechanical properties [5]-[7].

The effects of combination RE (Gd-La) and (Gd-Ce) have been investigated by Peng et al. [8] in three alloys with composition Mg-8Gd-0.6Zr-xRE ( $\mathrm{x}=0,1 \mathrm{La}, 1 \mathrm{Ce}$ wt.\%). Both as-cast microstructure of Lacontaining and Ce containing alloys found to form intermetallic phases with Gd substitution, $\operatorname{Mg}_{17}(\mathrm{La}, \mathrm{Gd})_{2}$ and $\mathrm{Mg}_{12}(\mathrm{Ce}, \mathrm{Gd})$ respectively. The alloy with $1 \%$ Ce addition exhibits the highest hardness, ultimate tensile strength, yield strength and approximately same tensile elongation of all alloys. Recently, Wang et al. [9] found that the microhardnes of $(\mathrm{Mg}, \mathrm{Zn})_{12}(\mathrm{La}, \mathrm{Ce})$ phases is $146.2 \mathrm{HV}$ in Mg-6.80La-2.83Ce-2.59Zn (wt.\%) alloy, which much higher than long period stacking ordered, LPSO phase (86.9HV) found in Mg-6.42Y2.49Zn (wt.\%) alloy. The matrices of both alloys reported to have very similar microhardnesses. Harder (Mg $\mathrm{Zn})_{12}(\mathrm{La}, \mathrm{Ce})$ phase increase the yield strength however reduce the elongation.

Based on aforementioned literatures, there is still lack of research in combination individual rare earth $\mathrm{Nd}$ and Ce elements particularly in Mg-Zn-Zr alloy. Therefore the aim of the present study is to investigate the effects of individual rare earth, $\mathrm{Nd}$ on microstructure characteristics and mechanical properties of as cast Mg-Ce-Zn-Zr alloy.

\section{Experimental Details}

The alloys were prepared in an electrical resistance furnace under a protective gas mixture of $\mathrm{Ar}+\mathrm{SF}_{6}$. Mg-3.1Ce-2.5Zn-0.6Zr (wt.\%) base alloy was melted in $\mathrm{H} 13$ steel crucible and 1.0, 2.0 and $3.0 \mathrm{wt} \% \mathrm{Nd}$ was added to melt at $730{ }^{\circ} \mathrm{C}$. After the addition the melt was stirred for a few minutes for the complete dissolution of $\mathrm{Nd}$ and to achieve uniform composition in melt before pouring into a preheated $\mathrm{H} 13$ steel permanent mould with dimension $40 \mathrm{~mm}$ in diameter and $40 \mathrm{~mm}$ in height.

The melt was allowed cooling in air then the samples for microstructural analysis were taken from the central section of ingots and then were ground and polished using standard methods. After polish the specimen for microstructural studies were etched with a reagent containing of $3 \mathrm{ml} \mathrm{HNO}_{3}$ and $97 \mathrm{ml}$ ethanol and then rinse with water. IMT iSolution DT V12.0 image analyser was used to examine the microstructure. Average grain sizes of the investigated alloys were measured quantitatively by using the linear intercept method based on ASTM standard E112-12 with approximately 500 intersections which required for obtaining better \% relative accuracy. The microstructure was characterized by optical microscopy (a Nikon optical microscope) and scanning electron microscopy SEM (JEOL JSM-6380LA) equipped with an EDS detector. The phase compositions of the investigated alloys were analyzed using SEM equipped with energy dispersive X-ray spectroscopy (EDS) system. X-ray diffraction (XRD) was carried out to confirm the phase identification by EDS using PANalytical X-pert ${ }^{3} \mathrm{X}$-ray diffractometer and the data was characterized by Highscore version 3.0e software.

Tensile specimen was produced according to ASTM standard B557M by CNC lathe machine (Yamazaki Mazak QTN100) with gauge diameter and length of $9 \mathrm{~mm}$ and $50 \mathrm{~mm}$ respectively. Tensile tests were 
performed by using Shimadzu Servopulser testing machine with tensile speed of $1 \mathrm{~mm} / \mathrm{min}$.

\section{Results And Discussion}

\subsection{Microstructure}

SEM micrograph of as-cast Mg-Ce-Zn-Zr alloy (base alloy) and the Nd-containing alloys (1Nd, $2 \mathrm{Nd}$ and $3 \mathrm{Nd}$ ) are shown in Fig. 1(a-d) respectively. Microstructure of all alloys mainly consists of black equiaxed $\alpha$ Mg matrices and bright secondary phases crystallized along grain boundaries. SEM observation indicates that increasing $\mathrm{Nd}$ addition leads to the refinement of $\alpha$-Mg grain size. In addition, increasing $\mathrm{Nd}$ leads to increase volume fraction of second phase at the grain boundary. This is consistent with the quantitative result of linear intercept measurement which is found that the average grain size of base alloy, $1 \mathrm{Nd}, 2 \mathrm{Nd}$ and $3 \mathrm{Nd}$ are $62.5 \mu \mathrm{m}, 53.4 \mu \mathrm{m}, 50.2 \mu \mathrm{m}$ and $44.5 \mu \mathrm{m}$ respectively. As a reference, average grain size of as cast Mg-Zn-Ce-Y-Zr alloys have been reported to be around 60-70 $\mu \mathrm{m}$ [10].

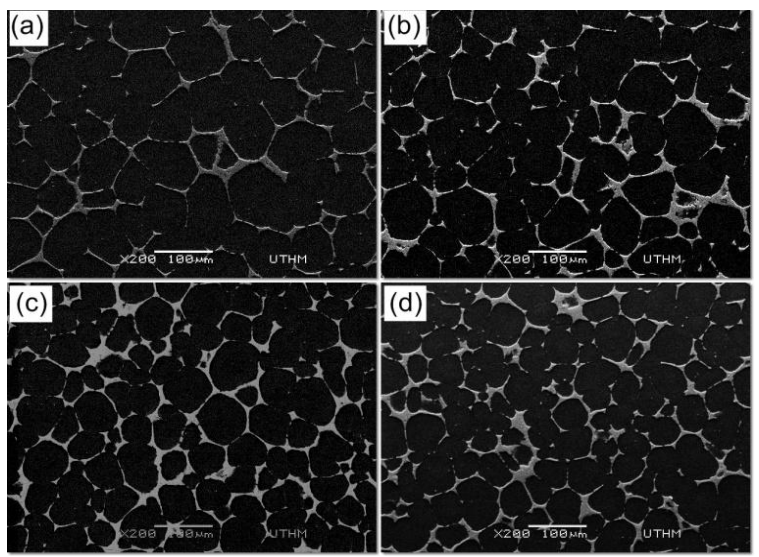

Fig. 1. SEM micrograph of as cast: (a) base alloy, (b) $1.0 \mathrm{wt} . \% \mathrm{Nd}$, (c) $2.0 \mathrm{wt} . \% \mathrm{Nd}$ and (d) $3.0 \mathrm{wt.} \% \mathrm{Nd}$.

The microstructure of base alloy consists of solid solution $\alpha$-Mg with discontinuous network of bright phase which is further identified as $(\mathrm{Mg}, \mathrm{Zn})_{12} \mathrm{Ce}$ intermetallic phase. The presence of the massive $\mathrm{Mg}_{12} \mathrm{Ce}$ type phase in this alloy is due to low solubility of Ce in Mg [11]. Fig. 2 shows the SEM micrograph at high magnification of the alloys and their corresponding EDS analysis to reveal alloying element in the selected areas. EDS analysis on the second phase of base alloy (point 1) indicates that the phase was enrich with Ce and also contains Zn element as shown by EDS result on the right side. The matrix found without Ce and contains small presence of $\mathrm{Zn}$ and $\mathrm{Zr}$ concentration as similar observed by Rzychoń et al. [12]. The low concentration of $\mathrm{Zn}$ solutioned in $\alpha$-Mg matrix suggested that high residual Zn element formed compound with Ce in Mg-Zn-Ce intermetallic phase, which concentrated at grain boundaries.

High concentration of Ce element at grain boundaries is within the expectation where the Ce elements are tend to segregated at front of solid liquid interface during solidification due to extremely low solid solubility of Ce in $\mathrm{Mg}$, particularly in the presence of $\mathrm{Zn}$ in the investigated alloys [13]. Ming-li et al. [14] found that the maximal solubility of $\mathrm{Zn}$ in $\mathrm{Mg}_{12} \mathrm{Ce}$ is about $7.8 \%$ (molar fraction) and identified the chemical formula as $\left(\mathrm{Mg}_{1-\mathrm{x}} \mathrm{Zn}_{\mathrm{x}}\right)_{12} \mathrm{Ce}$, which $\mathrm{Mg}$ is substituted by $\mathrm{Zn}$ and decreases the lattice parameter of the compound due to shorter atomic radius of $\mathrm{Zn}$ than $\mathrm{Mg}$. The EDS result consistence with the diffraction pattern of XRD peaks which correspond to $\mathrm{Mg}_{12} \mathrm{Ce}$-type phase (Reference code: 98-062-1495) with slight deviation in $2 \theta$ degree from the standard peaks as shown in Fig. 3(a). Typical $\alpha$-Mg peaks (Ref. code: 98-007-7908) are present in all investigated alloys.

The EDS analysis of point 1, 2, 3, and 4 in Fig. 2 are summarized in Table I. The analysis shows that the second phase of Nd-containing alloys enrich with $\mathrm{Nd}$ element. Moreover increasing $\mathrm{Nd}$ addition led to the 
enhancement of $\mathrm{Nd}$ concentration in that phase simultaneously increases the volume fraction of the second phase, consequently led to a bulky network phase type formation along grain boundary. Interestingly, when amount of $\mathrm{Nd}$ addition increases, concentration of Ce and $\mathrm{Zn}$ elements in the second phase gradually decrease. Furthermore, when the amount of $\mathrm{Nd}$ addition at $3.0 \mathrm{wt}$ \% which is at approximate composition of Ce in the base alloy (3.1 wt.\%), the $\mathrm{Nd}$ concentration in the second phase is found to be approximately equal with the Ce concentration as shown in Table I. For 3Nd alloy, EDS point analysis indicates Ce and $\mathrm{Nd}$ concentrations are $12.20 \mathrm{wt} . \%$ and $12.08 \mathrm{wt} . \%$ respectively.

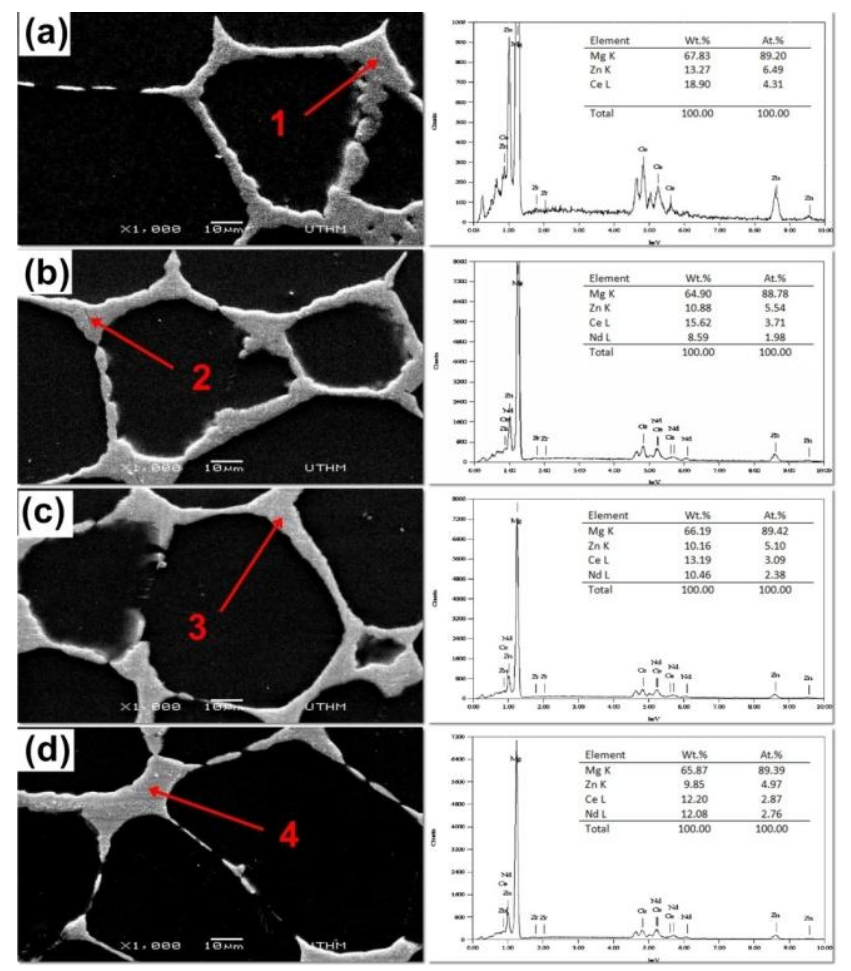

Fig.2. High magnification SEM micrograph and its correspond EDS point analysis of as-cast:

(a) Base alloy, (b) 1.0 wt. $\% \mathrm{Nd}$, (c) $2.0 \mathrm{wt} \% \mathrm{Nd}$ and (d) $3.0 \mathrm{wt} \% \mathrm{Nd}$.
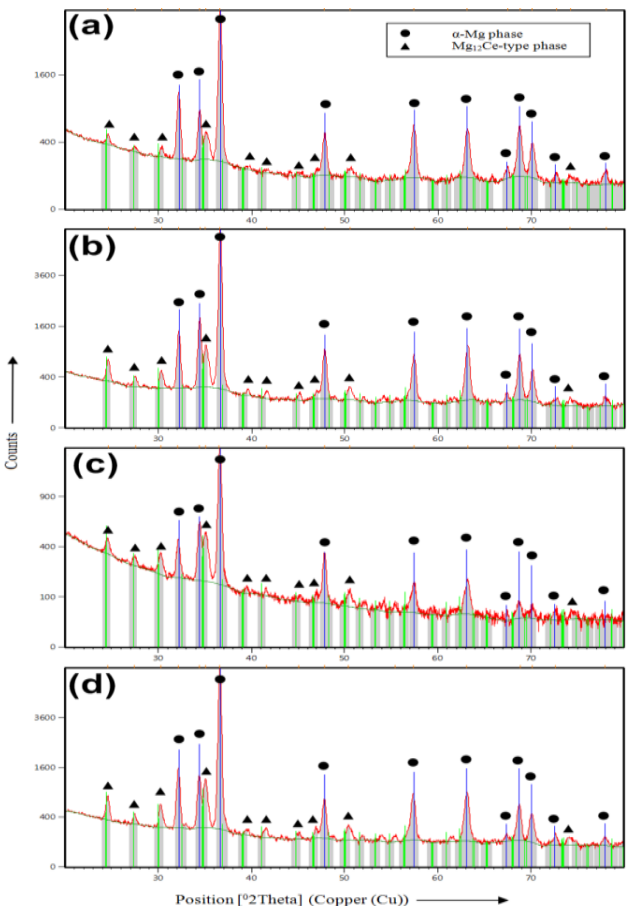

Fig. 3. XRD pattern of investigated alloys: (a) base alloy, (b) 1.0 wt.\% Nd, (c) 2.0 wt.\% Nd and (d) 3.0 wt.\% $\mathrm{Nd}$. 
Table 1. EDS Analysis of The Element Concentration (wt.\%) in Second Phase of Investigated Alloys

\begin{tabular}{|l|l|l|l|c|}
\hline \multirow{2}{*}{ Alloys } & \multicolumn{4}{|c|}{ Elements concentration } \\
\cline { 2 - 5 } & \multicolumn{1}{|c|}{$\boldsymbol{M g}$} & \multicolumn{1}{|c|}{$\boldsymbol{Z n}$} & $\boldsymbol{C} \boldsymbol{N}$ & $\boldsymbol{N d}$ \\
\hline Base & 67.83 & 13.27 & 18.90 & - \\
\hline $1 \mathrm{Nd}$ & 64.90 & 10.88 & 15.62 & 8.59 \\
\hline $2 \mathrm{Nd}$ & 66.19 & 10.16 & 13.19 & 10.46 \\
\hline $3 \mathrm{Nd}$ & 65.87 & 9.85 & 12.20 & 12.08 \\
\hline
\end{tabular}

As $\mathrm{Nd}$ amount rises up, the second phase increase rapidly due to low solid solubility of $\mathrm{Nd}$ in $\mathrm{Mg}$. Solid solubility of $\mathrm{Nd}$ in $\mathrm{Mg}$ is $3.6 \mathrm{wt} \%$ furthermore, the solubility decreases as the temperature drop, consequently Nd would likely segregate at grain boundary during solidification [11], [15].

SEM micrographs show no significant modification of the second phase morphology due to the increment of $\mathrm{Nd}$ concentration instead of increasing its volume fraction from a discontinuous of thin intermetallic network to the continuous of thick second phase precipitated along grain boundary, relatively. XRD analysis Fig. 3(b-d) also in agreement with the SEM observation, which indicates no presence of new significant peak except typical $\alpha$-Mg peaks and $\mathrm{Mg}_{12}$ Ce-type peaks in all $\mathrm{Nd}$ containing alloys. It is therefore can be deduced that there is complete solubility of $\mathrm{Nd}$ in $\mathrm{Mg}_{12} \mathrm{Ce}$ phase which Ce element is substituted by $\mathrm{Nd}$ to form $(\mathrm{Mg}, \mathrm{Zn})_{12}(\mathrm{Ce}, \mathrm{Nd})$ intermetallic phase in the present investigated alloys.

\subsection{Mechanical Properties}

Tensile properties of as-cast Mg-Ce-(Nd)-Zn-Zr alloys including $0.2 \%$ yield strength (YS), ultimate tensile strength (UTS) and \% elongation (\% E) are summarized in Fig. 4. It is observed that additions of $\mathrm{Nd}$ increase the yield strength and ultimate tensile strength of the as-cast Mg-Ce-Zn-Zr alloy. Yield strength and ultimate tensile strength increased by $6.66 \%$ and $3.62 \%$, respectively. In contrast, the elongation significantly decreased by $19.7 \%$ with the increasing of $\mathrm{Nd}$ addition. The result is strongly related to the $\mathrm{Nd}$ addition due to obvious modification effects on the morphologies of microstructure, which is; (a) grain refinement, and (b) increasing volume fraction of the second phase.

Rare earth is well known to have a beneficial on grain refinement of cast Mg alloys, particularly $\mathrm{La}, \mathrm{Ce}, \mathrm{Nd}$ and Pr which have low solubility in Mg. This is due to the enrichment of RE atoms at front of growing $\alpha$ dendrite solid-liquid interface, resulting in restriction of grain growth consequently leads to a finer grain. This is hypothesize based on observation of RE-containing phase concentrated at grain boundary [3].

Furthermore the present study found that EDS analysis exhibits significant gradual increase of $\mathrm{Nd}$ concentration in the RE-containing second phase which reinforces the aforementioned hypothesis. Moreover the present study shows an inverse relationship exists between grain size and yield strength which is obey the Hall-Petch law [10]. It is well known that the grain refinement in magnesium alloys is beneficial to the mechanical properties, particularly $0.2 \%$ yield strength based on Hall-Petch relationship [16]. Therefore increasing of yield strength and ultimate tensile strength might be attributed to the grain refinement.

Concentration of RE-intermetallic phase along grain boundaries enhances the strength of $\mathrm{Mg}$ alloys due to the pinning effect on the grain boundary migration [11], however it is deteriorate in a high volume fraction, bulky phase and continuous network morphology of intermetallic phase, particularly the elongation due to the local stress concentration during deformation at the interface between matrix and second phase, which is promotes the initiation and propagation of cracks and consequently result in decrease elongation of the investigated alloys [17]. 


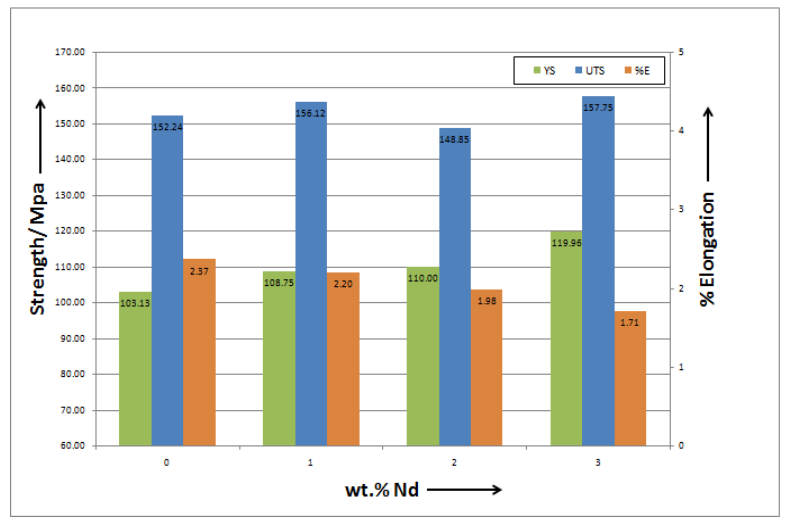

Fig. 4. Tensile properties of the as-cast investigated alloys.

\section{Conclusion}

Rare earth element $\mathrm{Nd}$ is added to $\mathrm{Mg}-3.1 \mathrm{Ce}-2.5 \mathrm{Zn}-0.6 \mathrm{Zr}$ alloy and the effects of $\mathrm{Nd}$ addition on microstructure and tensile properties of investigated alloys are investigated. The tensile properties are correlated with the microstructural studies. Microstructure of the base alloy consists of $\alpha-\mathrm{Mg}$ phase and discontinuous network of $\mathrm{Mg}_{12} \mathrm{Ce}$-type intermetallic phase along grain boundaries. As the phase contains $\mathrm{Zn}$, the compound formula could be suggested as $\left(\mathrm{Mg}, \mathrm{Zn}{ }_{12} \mathrm{Ce}\right.$ phase. The addition of $\mathrm{Nd}$ leads to the formation $(\mathrm{Mg}, \mathrm{Zn})_{12}(\mathrm{Ce}, \mathrm{Nd})$ phase, apart from typical $\alpha$-Mg phase. The concentration of $\mathrm{Nd}$ in the phase is gradually increases as the amount of $\mathrm{Nd}$ addition increases consequently increases the volume fraction of the second phase. $\mathrm{Nd}$ additions obviously refine the grain by approximately $19.68 \%$, increase both yield strength and ultimate tensile strength however significantly decrease the elongation. Both grain refinement and secondary phase, $(\mathrm{Mg}, \mathrm{Zn})_{12}(\mathrm{Ce}, \mathrm{Nd})$ are suggested as the main strengthening mechanisms in observed development of the yield strength and ultimate tensile strength in the present investigated alloy.

\section{Acknowledgment}

This research is funded by Exploratory Research Grant Scheme (ERGS), vot number E023, Ministry of Higher Education, Malaysia.

\section{References}

[1] Luo, A. A. (2013). Applications: Aerospace, automotive and other structural applications of magnesium. In M. O. Pekguleryuz, K. U. Kainer, \& A. A. Kaya (Eds.), Fundamentals of Magnesium Alloy Metallurgy (pp. 266-316). Cambridge UK: Woodhead Publishing Limited.

[2] Luo, A. A. (2013). Magnesium casting technology for structural applications. J. Magnes. Alloy., 1(1), 2-22.

[3] Ali, Y., Qiu, D., Jiang, B., Pan, F., \& Zhang, M. (2015). Current research progress in grain refinement of cast magnesium alloys : A review article. J. Alloys Compd., 619, 639-651.

[4] Pekguleryuz, M. O. (2013). Alloying behavior of magnesium and alloy design. In M. O. Pekguleryuz, K. U. Kainer, \& A. A. Kaya (Eds.), Fundamentals of Magnesium Alloy Metallurgy(pp. 152-196). Cambridge UK: Woodhead Publishing Limited.

[5] Tekumalla, S. , Seetharaman, S., Almajid, A., \& Gupta, M. (2015). Mechanical properties of magnesiumrare earth alloy systems: A Review. Metals, 5(1), 1-39.

[6] Zhu, S., Easton, M. A.,. Abbott, T. B., Gibson, M. A., \& Nie, J. F. (2016). The influence of individual rare earth elements (La, Ce, or $\mathrm{Nd}$ ) on creep resistance of die-cast magnesium alloy AE44. Adv. Eng. Mater., 18(6), 932-937.

[7] Gröbner, J., Hampl, M., Schmid-Fetzer, R., Easton, M. A., Zhu, S., Gibson, M. A., et al. (2012). Phase 
analysis of Mg-La-Nd and Mg-La-Ce alloys. Intermetallics, 28, 92-101.

[8] Peng, Q., Wang, J., Wu, Y., Meng, J., \& Wang, L. (2008). The effect of La or Ce on ageing response and mechanical properties of cast Mg-Gd-Zr alloys. Mater. Charact., 59(4), 435-439.

[9] Wang, J. Y., Saufan, A., Lin, P. H., Bor, H. Y., Lee, S., \& Kawamura, Y. (2014). Mechanical properties and strengthening behavior of Mg-Zn-MM alloy. Mater. Chem. Phys., 148(1-2), 28-31.

[10] Liu, L., Chen, X. H., Pan, F., Wang, Z., Liu, W., Cao, P., et al. (2015). Effect of Y and Ce additions on microstructure and mechanical properties of Mg-Zn-Zr alloys. Mater. Sci. Eng. A, 644, 247-253.

[11] Zhu, S. M., Gibson, M. A., Easton, M. A., \& Nie, J. F. (2010). The relationship between microstructure and creep resistance in die-cast magnesium-rare earth alloys. Scr. Mater., 63(7), 698-703.

[12] Rzychoń, T., Szala, J., \& Kielbus, A. (2012). Microstructure, castability, microstructural stability and mechanical properties of ZRE1 magnesium alloy. Arch. Metall. Mater., 57(1), 245-252.

[13] Kevorkov, D., \& Pekguleryuz, M. (2009). Experimental study of the Ce-Mg- Zn phase diagram at $350^{\circ} \mathrm{C}$ via diffusion couple techniques. J. Alloys Compd., 478, 427-436.

[14] Huang, M. L., Li, H. X., Ding, H., Bao, L., Ma, X. B., \& Hao, S. M. (2012). Intermetallics and phase relations of Mg-Zn-Ce alloys at $400^{\circ} \mathrm{C}$. Trans. Nonferrous Met. Soc. China, 22, 539-545.

[15] Liu, X., Le, Q., Zhang, Z., Bao, L., \& Cui, J. (2016). Effects of Nd/Gd value on the microstructures and mechanical properties of Mg-Gd-Y-Nd-Zr alloys. J. Magnes. Alloy., 4(1), 214-219.

[16] Yang, Z., Li, J., Zhang, J., Lorimer, G., \& Robson, J. (2008). Review on research and development of magnesium alloys. Acta Metall. Sin. (English Lett.), 21(5), 313-328.

[17] Zhang, J., Kang, Z., \& Zhou, L. (2015). Microstructure evolution and mechanical properties of Mg-Gd-NdZn-Zr alloy processed by equal channel angular pressing. Mater. Sci. Eng. A, 647, 184-190.

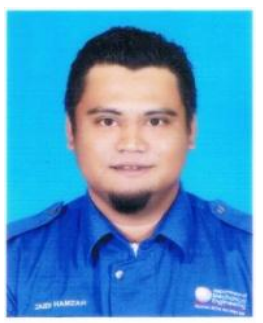

Mohd Zaidi Bin Hamzah was born in Kelantan, Malaysia, in 1982. He received the B. E. degree in Mechanical Engineering from the Kolej Universiti Teknologi Tun Hussein Onn, Batu Pahat, Malaysia in 2005 and the M. Edu degree in technical and vocational from Universiti Tun Hussien Onn, Batu Pahat, Malaysia in 2007. He is now a part time student in Doctor of Philosophy in Mechanical Engineering at Universiti Tun Hussein on Malaysia, Batu Pahat, Malaysia under supervision of both Associate Professor Dr. Rosli Bin Ahmad and co-supervisor Dr. Muhammed Basher A. Asmael. In 2007, he joined the Department of Mechanical Engineering, Politeknik Port Dickson, Malaysia as a lecturer. In 2012 he was transferred to Politeknik Mukah Sarawak, Malaysia and in 2016 he moved to Politeknik Sultan Haji Ahmad Shah, Pahang, Malaysia. His work focuses specifically on the casting and solidification of magnesium alloys with rare earth additives with cooling curve thermal analysis (CC-CCA). He works with rare earth Gadolinium, Samarium, Neodymium, Yttrium, Praseodymium and Erbium. Mr. Zaidi is a life member of Boards Of Engineer Malaysia. 